\title{
Obrada komunalne otpadne vode membranskim procesima
}

\section{Dolar, M. Racar, K. Košutić, N. Čavarović i K. Karadakić}

Fakultet kemijskog inženjerstva i tehnologije, Sveučilište u Zagrebu

\begin{abstract}
Sažetak
Industrijalizacija, porast populacije i urbanizacija glavni su uzroci stvaranja sve većih količina komunalnih otpadnih voda (KOV) koje, neobrađene, predstavljaju ozbiljnu prijetnju prirodnim vodonosnicima. Radi zaštite okoliša i prirodnih resursa potrebno je primjenjivati visokoučinkovite i okolišu naklonjene tehnologije obrade KOV-a. Cilj ovog rada bio je obrada KOV-a naprednim membranskim postupcima; membranskim bioreaktorom (MBR) te dodatnom obradom MBR efluenta s nanofiltracijom (NF) i reverznom osmozom (RO). Laboratorijska i pilot-obrada KOV-a MBR-om rezultirala je smanjenjem kemijske potrošnje kisika (KPK), biokemijske potrošnje kisika $\left(\mathrm{BPK}_{5}\right)$, mutnoće i suspendiranih tvari za više od 92 \%. Mikrobiološki parametri smanjeni su za 4,12 $\log _{10}$ do 4,88 $\log _{10}$. Naknadna obrada MBR efluenta s RO/NF membranama (XLE i NF270) pokazala je dodatno smanjenje svih mjerenih parametara.

\section{Ključne riječi}

Komunalna otpadna voda, membranski procesi, membranski bioreaktor, nanofiltracija, reverzna osmoza
\end{abstract}

\section{Uvod}

Količina otpadne vode nastala u kućanstvima i industriji sve više raste s povećanjem broja stanovnika, intenzivnom urbanizacijom, gospodarskim razvojem i podizanjem životnog standarda. ${ }^{1}$ Sve to zajedno ozbiljan je stres na postojeće vodene resurse koji su dostatni tek u određenim dijelovima svijeta. ${ }^{2}$ Goleme količine generirane komunalne otpadne vode (KOV) je stoga potrebno iskoristiti, tj. kvalitetno obraditi, prije svega radi zaštite vodenog ekosustava te ljudskog zdravlja. T. Sato i sur. ${ }^{3}$ prikazali su udio obrađenih otpadnih voda u svijetu prema ekonomskim kategorijama zemalja s niskim, nižim srednjim, višim srednjim i visokim dohotkom. Pokazalo se da zemlje s visokim dohotkom obrađuju u prosjeku $70 \%$ proizvedene otpadne vode, zemlje s višim srednjim dohotkom 38 \%, nižim srednjim $28 \%$ i zemlje s niskim dohotkom obrađuju tek $8 \%$ proizvedene otpadne vode.

U Europi se obrađuje 71 \% otpadnih voda zahvaljujući djelomično visokoj javnoj svijesti o zaštiti okoliša i ljudskog zdravlja, tehnološkom napretku metoda pročišćavanja otpadnih voda te ulaganjima nacionalnih vlada u sustave za pročišćavanje otpadnih voda. ${ }^{3} \cup$ Hrvatskoj se generira prosječno 350 milijuna $\mathrm{m}^{3}$ otpadne vode a izgrađeno je oko 150 uređaja za pročišćavanje otpadnih voda (UPOV), ukupnog kapaciteta 4,33 milijuna ekvivalent stanovnika (ES), od čega 1,87 milijuna ES čine uređaji s I. stupnjem pročišćavanja, 2,14 milijuna ES uređaji s II. stupnjem pročišćavanja te 0,32 milijuna ES s III. stupnjem pročišćavanja. ${ }^{4}$

Zbog sve strožih zakonskih regulativa poseže se za novim i modernijim tehnologijama obrade otpadnih voda. Membranski procesi kao što su membranski bioreaktor (MBR), nanofiltracija (NF) i reverzna osmoza (RO) postaju sve po-

*Autor za dopisivanje: doc. dr. sc. Davor Dolar, e-pošta: dolar@fkit.hr pularnije i prihvaćenije metode obrade otpadnih voda. Konkurentnost membranskih uređaja naspram klasičnih UPOV-a je u boljoj kvaliteti efluenta, boljem i učinkovitijem uklanjanju novih zagađivala ${ }^{5,6}$ i mikroorganizama ${ }^{5,7}$ te manjoj proizvodnji otpadnog mulja kod MBR-a. ${ }^{5}$ Zbog ekonomičnosti procesa ${ }^{8}$ primjena MBR-a u posljednjih 10 godina u znatnom je rastu. U 2010. godini u svijetu je $\mathrm{s}$ MBR-om obrađeno oko $400 \cdot 10^{3} \mathrm{~m}^{3} \mathrm{dan}^{-1}$ otpadne vode, dok je 2018. obrađeno oko $5200 \cdot 10^{3} \mathrm{~m}^{3} \mathrm{dan}^{-1}$. $^{9}$

Cilj ovog istraživanja bio je obrada realne komunalne otpadne vode s laboratorijskim i MBR pilot-uređajem te završna obrada laboratorijskog MBR efluenta s NF i RO membranama.

\section{Eksperimentalni dio}

Realna komunalna otpadna voda obrađena je hibridnim postupkom MBR-NF/RO. Realni uzorak KOV-a uzorkovan je na UPOV-u aglomeracije Čakovec, koji sačinjavaju otpadne vode kućanstva, oborinske otpadne vode i tehnološke otpadne vode gospodarstva koje su istim kanalizacijskim sustavom dovedene do UPOV-a Čakovec. Uzorkovanje je provedeno nakon grubih rešetki i pjeskolova/ mastolova.

\subsection{Laboratorijski i MBR pilot-uređaj}

U prvoj fazi obrade KOV-a upotrijebljeni su laboratorijski i MBR pilot-uređaji koji su opremljeni odgovarajućim senzorima (tlak, temperatura, protok i razina) a uvjeti rada prikazani su u tablici 1. Za nadzor rada MBR-a i prikupljanje podataka primijenjen je Alpha Programming (SW0D5ALVLS-EU) sustav (Mitsubishi Electric Corporation, Japan). Shematski prikaz laboratorijskog i MBR pilot-uređaja prika- 


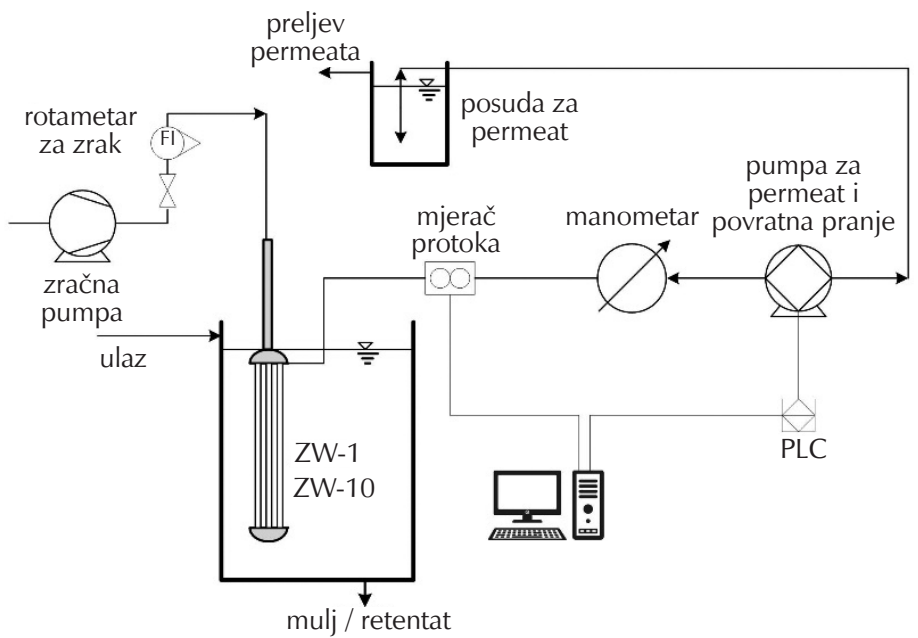

Slika 1 - Shematski prikaz laboratorijskog i MBR pilot-uređaja

Fig. 1 - Schematic presentation of laboratory and pilot MBR

zan je na slici 1. Volumen reaktora iznosio je 5 I (laboratorijski) i 200 I (pilot) a sadržavao je aktivni mulj dopremljen iz UPOV-a aglomeracije Čakovec.

Tablica 1 - Uvjeti rada laboratorijskog i MBR pilot-uređaja Table 1 - Working conditions for laboratory and pilot MBR

\begin{tabular}{l|c|c}
\hline & Laboratorijski MBR & Pilot-MBR \\
\hline membrana & ZW-1 & ZW-10 \\
\hline fluks $/ \mathrm{I} \mathrm{m}^{-2} \mathrm{~h}^{-1}$ & $24,64 \pm 2,67$ & 40 \\
\hline $\begin{array}{l}\text { hidrauličko vrijeme } \\
\text { zadržavanja (HRT)/h }\end{array}$ & 4,4 & 5,5 \\
\hline koncentracija mulja $/ \mathrm{gl}^{-1}$ & 8,3 & 8,6 \\
\hline protok zraka/I min $^{-1}$ & 20 & 75 \\
\hline
\end{tabular}

Sastavni dio MBR-a bila je ultrafiltracijska (UF) membrana u obliku šupljih vlakana. U laboratorijskom MBR-u upotrijebljena je ZeeWeed 1 membrana (ZW-1) površine $0,046 \mathrm{~m}^{2}$ i nominalne veličine pora $0,02 \mu \mathrm{m}$, a u MBR pilot-uređaju ZeeWeed 10 membrana (ZW-10) površine $0,9 \mathrm{~m}^{2}$ i nominalne veličine pora $0,04 \mu \mathrm{m}$. Obje membrane su dobavljene od GE Water \& Process Technologies, Mađarska. Pokusi u oba pokusa trajali su 5 dana. U laboratorijskom MBR-u komunalna otpadna voda dozirala se kontinuirano iz spremnika volumena 20 I te je spremnik svaki dan punjen svježom otpadnom voda koja je čuvana na temperaturi do $10{ }^{\circ} \mathrm{C}$. U pilot-uređaju komunalna otpadna voda je kontinuirano dozirana iz UPOV-a aglomeracije Čakovec.

\subsection{Laboratorijski NF/RO uređaj}

MBR efluent dodatno je obrađen na NF/RO laboratorijskom uređaju koji je detaljno opisan u E. Dražević i sur. ${ }^{10}$
MBR efluent (10 I) cirkulirao je kroz membransku jedinicu protokom od $3 \mathrm{I} \mathrm{min}^{-1}$ (brzina strujanja $0,75 \mathrm{~m} \mathrm{~s}^{-1}$ ). Membrana je selektivno zadržavala retentat, a propuštala permeat. Tlak je praćen manometrom. Rabljene su nanofiltracijska NF270 i RO XLE membrane istog proizvođača (Dow-Filmtec, SAD). Karakteristike membrana prikazane su u $D$. Dolar i sur. ${ }^{11}$

Membrane su isprane sa 7 I demineralizirane vode kako bi se uklonio konzervans. Izvršena je tlačna predobrada odnosno stabilizacija protoka membrana demineraliziranom vodom pri tlaku od 15 bar u trajanju od 1 h. $U$ drugoj fazi obrađivao se MBR efluent pri tlaku od 12 bar u trajanju od 3 h. U završnoj fazi NF/RO obrade membrane su ispirane demineraliziranom vodom u trajanju od $30 \mathrm{~min}$. U svim fazama protok je praćen pomoću tehničke vage KERN 44035A (Njemačka) a masa je bilježena računalno svakih $10 \mathrm{~s}$.

\subsection{Analiza vode}

Komunalna otpadna voda, MBR efluent i NF/RO permeat analizirani su prema standardnim metodama; ${ }^{12} \mathrm{pH}$, kemijska potrošnja kisika (KPK), biokemijska potrošnja kisika $\left(\mathrm{BPK}_{5}\right)$, mutnoća, miris, električna provodnost, ukupne suspendirane čestice (TSS), ukupna koncentracija ugljika (TC), koncentracija anorganskog ugljika (IC), koncentracija otopljenog organskog ugljika (DOC), amonijak i mikrobiološka analiza (ukupne koliformne bakterije (KB), Escherichia coli (EC), Enterococcus (ENT), broj kolonija $36{ }^{\circ} \mathrm{C}$ i $22{ }^{\circ} \mathrm{C}$ (BK36 i BK22)). Za električnu provodnost i pH upotrijebljen je multimetar HandyLab 680 (SI Analytics, Njemačka), za mutnoću turbidimetar Turb 430 IR/Set (WTW, Njemačka), KPK i BPK ${ }_{5}$ sa spektrofotometrom Hach Lange DR3900 (Njemačka), TC, IC i DOC s analizatorom ugljika TC- $\mathrm{V}_{\mathrm{ws}}$ (Shimadzu, Japan). Amonij je određivan ionskim kromatografom DIONEX ICS-3000 (ThermoFischerScientific, SAD).

Za određivanje mikrobioloških parametara upotrijebljena su razrjeđenja od $10^{-3}$ do $10^{-6}$. Koliforme bakterije, EC i 
ENT određivane su primjenom metode membranske filtracije kroz filtar papir od celuloznog estera s promjerom pora od 0,45 um. Kao hranjiva podloga za ukupne koliformne bakterije i EC upotrijebljena je Chromogenic coliform agar (Biolife, Italija), a za Enterokoke selektivna hranjiva podloga Slanetz-Bartley. Nakon filtracije uzorka KB inkubirane su na $36{ }^{\circ} \mathrm{C} / 24 \mathrm{~h}, \mathrm{EC}$ na $44^{\circ} \mathrm{C} / 24 \mathrm{~h}$, a ENT na $36^{\circ} \mathrm{C} / 48 \mathrm{~h}$. Za suspektne kolonije EC primijenjen je završni biokemijski test Bactident E. coli (Merch). Nakon kvantifikacije ENT postojanost bakterija je potvrđena na Bile aesculin agaru (Biolife, Italija), koji svojim sastavom inhibira rast ostalih gram pozitivnih bakterija. BK36 i BK22 određivan je metodom razmaza na Yeast extract agaru. Inkubacija za BK36 iznosila je 48 h, a za BK22 72 h. Granica detekcije za KB, EC i ENT bila je $1 \mathrm{CFU} 100 \mathrm{ml}^{-1}$, a za ostale mikrobiološke parametre $1 \mathrm{CFU} 1 \mathrm{ml}^{-1}$.

\section{Rezultati i rasprava}

Komunalna otpadna voda obrađena je najprije u laboratorijskom a potom na MBR pilot-uređaju. U tablici 2 prikazani su fizikalno-kemijski i mikrobiološki parametri KOV-a koji su upotrijebljeni za oba uređaja te parametri dobivenog MBR efluenta. S obzirom na to da istraživanja nisu rađena istodobno, vidljiva je razlika u ulaznim parametrima, posebice u KPK-u i TSS-u. Razlozi odstupanja su značajne promjene u sastavu otpadne vode koje ovise o trenutačnim aktivnostima u području koje gravitira na UPOV. Najveća razlika dobivena je za TSS koji je tijekom istraživanja na laboratorijskom uređaju i iznosila je $550 \mathrm{mgl}^{-1}$, a na pilotuređaju $8661 \mathrm{~g} \mathrm{I}^{-1}$. KPK vrijednost za vrijeme pilot-istraži- vanja bila je dva puta veća, te je vjerojatno doprinos visokoj vrijednosti TSS za pilot-uređaj anorganskog porijekla.

Aktivni mulj je pregledan mikroskopski te su pronađeni Rotaria, Suctorida i Vorticella sp. kao tipični mikroorganizmi koji se rabe za obradu KOV-a. S aspekta razgradnje organskih tvari, vidljivo je da su laboratorijski i pilot-MBR imali sličnu učinkovitost smanjenja BPK B $_{5}>99 \%$ za laboratorijski, $97 \%$ za pilot) i KPK (92\% za laboratorijski, $90 \%$ za pilot), što odgovara vrijednostima dobivenim $u$ radu $M$. Matošić i sur. ${ }^{13} \mathrm{~S}$ druge strane, MBR u oba mjerila potpuno (100 \%) je uklonio TSS i gotovo potpuno smanjio mutnoću (99,0 \% laboratorijski i 99,9 \% MBR pilot-uređaj). Dakle, i u laboratorijskom i pilot-uređaju potvrdila se ključna uloga UF membrane, a to je uklanjanje koloida i suspendiranih čestica, ${ }^{14}$ što povlači za sobom veliko smanjenje mutnoće i TSS. Jedina značajnija razlika pojavila se u promjeni $\mathrm{pH}$ vrijednosti efluenta, koji je u laboratorijskom uređaju porastao, a na pilot-MBR-u se smanjio. Takva razlika u promjeni pH vrijednosti može proizlaziti iz nekonzistentnog sastava ulazne otpadne vode kod pilot-postrojenja te razlike u aeraciji reaktora.

Uz fizikalno-kemijske parametre praćeni su i mikroorganizmi te su njihove koncentracije prikazane u tablici 2. Međutim, zbog nemogućnosti određivanja mikroorganizama tijekom obrade KOV-a na laboratorijskom MBR-u oni su određivani samo na pilot-uređaju. Vidljivo je da su prisutni svi praćeni mikroorganizmi, od kojih je najviše $\mathrm{KB} u$ iznosu od $1,7 \cdot 10^{7} \mathrm{CFU} 100 \mathrm{ml}^{-1}$, a najmanje ENT $6 \cdot 10^{5}$ CFU $100 \mathrm{ml}^{-1}$. Uklanjanje mikroorganizama na pilot-MBR-u kretalo se od 4,12 $\log _{10}$ za BK36 i 4,88 $\log _{10}$ za KB. Iz tablice 2 se može primijetiti da praćeni mikroorganizmi nisu u potpunosti uklonjeni, što i nije bilo očekivano. Ra-

Tablica 2 - Fizikalno-kemijski parametri i mikroorganizmi KOV-a (Ulaz) i MBR efluenta za laboratorijski i pilot-MBR Table 2 - Physicochemical parameters and microorganisms of MWW (Ulaz) and MBR effluent (Efluent) for laboratory and pilot MBR

\begin{tabular}{|c|c|c|c|c|c|}
\hline & \multirow[b]{2}{*}{ jedinica } & \multicolumn{2}{|c|}{ Laboratorijski MBR } & \multicolumn{2}{|c|}{ Pilot-MBR } \\
\hline & & Ulaz & Efluent & Ulaz & Efluent \\
\hline $\mathrm{pH}$ & - & 7,24 & 7,73 & 7,62 & 6,83 \\
\hline KPK & $\mathrm{mg} \mathrm{O}_{2} \mathrm{I}^{-1}$ & 309 & 24,4 & 615 & 60 \\
\hline $\mathrm{BPK}_{5}$ & $\mathrm{mg} \mathrm{O}_{2} \mathrm{I}^{-1}$ & 461 & $<4$ & 330 & 11 \\
\hline mutnoća & NTU & 89,30 & 0,92 & 95,2 & 0,05 \\
\hline TSS & $\mathrm{mg} \mathrm{l}^{-1}$ & 550 & 0 & 8661 & 0 \\
\hline vodljivost & $\mu S \mathrm{~cm}^{-1}$ & 1596 & 1360 & 1125 & 913 \\
\hline amonij & $\left.m g\right|^{-1}$ & & & & 1,2957 \\
\hline $\mathrm{TC}$ & $\mathrm{mg} \mathrm{l}^{-1}$ & 202,3 & 43,51 & 178,3 & 46,50 \\
\hline $\mathrm{IC}$ & $\mathrm{mg} \mathrm{l}^{-1}$ & 114,8 & 27,24 & 102,10 & 3,924 \\
\hline DOC & $\left.m g\right|^{-1}$ & 87,50 & 16,27 & 76,20 & 42,58 \\
\hline koliformne bakterije & CFU $100 \mathrm{ml}^{-1}$ & $2,8 \cdot 10^{6}$ & & $1,7 \cdot 10^{7}$ & 224 \\
\hline Escherichia coli & CFU $100 \mathrm{ml}^{-1}$ & $2,4 \cdot 10^{6}$ & & $4,0 \cdot 10^{6}$ & 56 \\
\hline Enterokoki & CFU $100 \mathrm{ml}^{-1}$ & $6 \cdot 10^{4}$ & & $6 \cdot 10^{5}$ & 6 \\
\hline broj kolonija $36^{\circ} \mathrm{C}$ & CFU $1 \mathrm{ml}^{-1}$ & $1,8 \cdot 10^{6}$ & & $3,7 \cdot 10^{6}$ & 282 \\
\hline broj kolonija $22{ }^{\circ} \mathrm{C}$ & CFU $100 \mathrm{ml}^{-}$ & $1,8 \cdot 10^{6}$ & & $8,0 \cdot 10^{6}$ & 236 \\
\hline
\end{tabular}


Tablica 3 - Fizikalno-kemijski parametri MBR efluenta (“Ulaz” za NF270 i XLE membrane) i RO/NF permeati Table 3 - Physicochemical parameters of MBR effluent ("Ulaz" for NF270 and XLE membranes) and RO/NF permeates

\begin{tabular}{c|c|c|c|c|c}
\hline & & \multicolumn{2}{|c|}{ NF270 } & \multicolumn{2}{c}{ XLE } \\
\hline $\mathrm{pH}$ & Jedinica & Ulaz & Permeat & Ulaz & Permeat \\
\hline $\mathrm{KPK}$ & - & 7,81 & 7,82 & 7,84 & 7,15 \\
\hline $\mathrm{BPK}_{5}$ & $\mathrm{mg} \mathrm{O}_{2} \mathrm{I}^{-1}$ & 22,70 & $<5$ & 23,80 & 6,67 \\
\hline $\mathrm{mutnoća}^{*}$ & $\mathrm{NTU}_{2} \mathrm{I}^{-1}$ & 13,00 & $<4$ & 13,00 & $<4$ \\
\hline TSS & $\mathrm{mg} \mathrm{I}^{-1}$ & - & - & - & 0,10 \\
\hline vodljivost & $\mu \mathrm{Cm}^{-1}$ & 1000 & 444 & 1083 & - \\
\hline amonij & $\mathrm{mgl}^{-1}$ & - & - & - & - \\
\hline $\mathrm{TC}$ & $\mathrm{mgl}^{-1}$ & 69,35 & 9,93 & 59,75 & 2,938 \\
\hline IC & $\mathrm{mgl}^{-1}$ & 42,35 & 9,00 & 42,33 & 0,772 \\
\hline DOC & $\mathrm{mgl}^{-1}$ & 27,01 & 0,926 & 17,42 & 2,166 \\
\hline
\end{tabular}

zlog je što se UF membrane karakteriziraju kao membrane koje uklanjanju viruse i bakterije. ${ }^{14}$ Kao potvrda tome je i veličina $K B$ promjera $0,6-1,2 \mu \mathrm{m}$ i duljina $2-3 \mu \mathrm{m}$, a veličina pora za ZW-10 membranu je 0,04 $\mu \mathrm{m}$. K. Zhang $i$ K. Farahbakhsh ${ }^{7}$ također su prikazali prisutnost KB u MBR efluentu u iznosu od 240 CFU $100 \mathrm{ml}^{-1}$ i kao razlog su naveli stvaranje biofilma u cijevima uređaja.

Međutim, navedeni rezultati, bez obzira što je veličina pora ispitivanih membrana ZW-1 0,02 $\mu \mathrm{m}$ i ZW-10 0,04 $\mu \mathrm{m}$, upućuju na to da su rezultati dobiveni na laboratorijskom MBR-u prikladni za procjenu učinkovitosti i optimizaciju MBR-a na veće mjerilo, u tom slučaju na pilot-MBR-a. Nadalje, takvo poklapanje dvaju mjerila ukazuje na mogućnost procjenjivanja učinkovitosti većih mjerila na industrijskoj razini.

Prema dobivenim rezultatima jedino DOC za MBR pilot-uređaj ne zadovoljava uvjete graničnih vrijednosti emisija otpadnih voda za ispuštanje u površinske vode (NN 80/2013, 43/2014, 27/2015, 3/2016). U posljednjih nekoliko godina pojavljuje se sve veći interes oporabe vode u svrhu očuvanja prirodnih resursa. Ukoliko se otpadna voda želi ponovno upotrijebiti za navodnjavanje, zalijevanje zelenih površina, potrebna je dodatna obrada u industrijskim postrojenjima iz kojih dolaze otpadne vode. Prema EU smjernicama za navodnjavanje MBR efluent ne zadovoljava koncentraciju Escherichie coli s obzirom na to da njihova koncentracija treba biti $\leq 10$ CFU $100 \mathrm{ml}^{-1}$. S druge strane, prema smjernicama Svjetske zdravstvene organizacije $(\mathrm{WHO})$ salinitet prikazan pomoću vodljivost treba biti $<700 \mu \mathrm{S} \mathrm{cm}^{-1}$. U tu svrhu NF i RO pokazuju velik potencijal s obzirom na odlično uklanjanje organskih tvari i soli. Zbog toga je efluent MBR laboratorijskog uređaja dodatno obrađen s rahlom nanofiltracijskom (NF270) membranom i reverzno osmotskom (XLE) membranom. Rezultati permeata NF270 i XLE membrana prikazani su u tablici 3, u kojoj je vidljivo visoko smanjenje svih praćenih parametara. Gotovo svi uzorci za KPK i $\mathrm{BPK}_{5}$ bili su ispod granice detekcije uređaja $\left(<5 \mathrm{mg} \mathrm{O}_{2} \mathrm{I}^{-1}\right)$ a ne postoji ni velika razlika između NF i RO membrane. Uočljiva razlika između ispitanih membrana je u smanjenju vodljivosti s obzirom na to da je s NF270 membranom vodljivost smanjena za 55,6 \%, a s XLE za 94,9\%. Razlog leži u veličini pora membrana s obzirom na to da XLE membrana ima pore manje od $1 \mathrm{~nm}$, a NF270 je predstavnik rahlih NF membrana, s porama veličine do $2 \mathrm{~nm} .{ }^{15}$

\section{Zaključak}

Utvrđena je visoka učinkovitost obrade realnih uzoraka komunalne otpadne vode na laboratorijskom i MBR pilot-uređaju, pri čemu su mutnoća, TSS, $\mathrm{KPK}, \mathrm{BPK}_{5}$ smanjeni za više od $92 \%$, dok su postignuti mikrobiološki parametri $4,12-4,88 \log _{10}$. Time se omogućuje sigurno ispuštanje obrađene komunalne otpadne vode u prirodne vodonosnike. Usporedba rezultata dobivenih na laboratorijskom i pilot-uređaju ukazuje na mogućnost uvećanja mjerila. Naknadnom obradom MBR efluenta s RO (XLE) i NF (NF270) membranama dobiven je efluent (permeat) dodatno poboljšane kvalitete.

\section{ZAHVALA}

Ovaj rad financiran je (1.492.908,72 HRK) u sklopu Programa Vlade Republike Hrvatske za poticanje istraživačkih i razvojnih aktivnosti u području klimatskih promjena za razdoblje od 2015. do 2016. godine uz podršku Ministarstva znanosti i obrazovanja, Ministarstva zaštite okoliša i prirode te energetske učinkovitosti i Hrvatske zaklade za znanost, u sklopu projekta Izravna oporaba komunalne otpadne vode za navodnjavanje membranskim tehnologijama (ReHOHMem) (PKP-2016-06-8522). 


\section{Popis kratica i simbola List of abbreviations and symbols}

\begin{tabular}{|c|c|}
\hline BR22 & $\begin{array}{l}\text { - broj kolonija } 22 \\
\text { - total colony count at } 22{ }^{\circ} \mathrm{C}\end{array}$ \\
\hline BK36 & $\begin{array}{l}\text { - broj kolonija } 36^{\circ} \mathrm{C} \\
\text { - total colony count at } 36^{\circ} \mathrm{C}\end{array}$ \\
\hline $\mathrm{BPK}_{5}$ & $\begin{array}{l}\text { - biokemijska potrošnja kisika } \\
\text { - biochemical oxygen demand }\end{array}$ \\
\hline DOC & $\begin{array}{l}\text { - otopljeni organski ugljik } \\
\text { - dissolved organic carbon }\end{array}$ \\
\hline $\mathrm{EC}$ & - Escherichia coli \\
\hline ENT & $\begin{array}{l}\text { - Enterokokum } \\
\text { - Enterococcus }\end{array}$ \\
\hline ES & $\begin{array}{l}\text { - ekvivalent stanovnika } \\
\text { - population equivalent }\end{array}$ \\
\hline HRT & $\begin{array}{l}\text { - hidrauličko vrijeme zadržavanja } \\
\text { - hydraulic retention time }\end{array}$ \\
\hline IC & $\begin{array}{l}\text { - anorganski ugljik } \\
\text { - inorganic carbon }\end{array}$ \\
\hline KB & $\begin{array}{l}\text { - ukupne koliforme bakterije } \\
\text { - total coliform bacteries }\end{array}$ \\
\hline KPK & $\begin{array}{l}\text { - kemijska potrošnja kisika } \\
\text { - chemical oxygen demand }\end{array}$ \\
\hline KOV & $\begin{array}{l}\text { - komunalna otpadna voda } \\
\text { - municipal wastewater }\end{array}$ \\
\hline MBR & $\begin{array}{l}\text { - membranski bioreaktor } \\
\text { - membrane bioreactor }\end{array}$ \\
\hline NF & $\begin{array}{l}\text { - nanofiltration } \\
\text { - nanofiltration }\end{array}$ \\
\hline RO & $\begin{array}{l}\text { - reverzna osmoza } \\
\text { - reverse osmosis }\end{array}$ \\
\hline TC & $\begin{array}{l}\text { - ukupni ugljik } \\
\text { - total carbon }\end{array}$ \\
\hline TSS & $\begin{array}{l}\text { - ukupne suspendirane čestice } \\
\text { - total suspended solids }\end{array}$ \\
\hline UPOV & $\begin{array}{l}\text { - uređaj za pročišćavanje otpadnih voda } \\
\text { - wastewater treatment }\end{array}$ \\
\hline ZW-1 & - ZeeWee 1 \\
\hline ZW-10 & - ZeeWee 10 \\
\hline
\end{tabular}

\section{Literatura \\ References}

1. K. S. Balkhair, M.A. Ashraf, Field accumulation risks of heavy metals in soil and vegetable crop irrigated with sewage water in western region of Saudi Arabia, Saudi J. Biol. Sci. 23 (2016) S32-S44, doi: https://doi.org/10.1016/j.sjbs.2015.09.023.

2. C. A. Quist-Jensen, F. Macedonio, E. Drioli, Membrane tech- nology for water production in agriculture: Desalination and wastewater reuse, Desalination 364 (2015) 17-32, doi: https://doi.org/10.1016/j.desal.2015.03.001.

3. T. Sato, M. Qadir, S. Yamamoto, T. Endo, A. Zahoor, Global, regional, and country level need for data on wastewater generation, treatment, and use, Agricult. Water Manag. 130 (2013) 1-13, doi: https://doi.org/10.1016/j. agwat.2013.08.007.

4. L. Ostroški, Statistički ljetopis Republike Hrvatske 2018., Državni zavod za statistiku, Zagreb, 2018.

5. A. T. Besha, A. Y. Gebreyohannes, R. A. Tufa, D. N. Bekele, E. Curcio, L. Giorno, Removal of emerging micropollutants by activated sludge process and membrane bioreactors and the effects of micropollutants on membrane fouling: A review, J. Environ. Chem. Eng. 5 (2017) 2395-2414, doi: https://doi. org/10.1016/j.jece.2017.04.027.

6. J. Radjenović, M. Petrović, D. Barceló, Fate and distribution of pharmaceuticals in wastewater and sewage sludge of the conventional activated sludge (CAS) and advanced membrane bioreactor (MBR) treatment, Water Res. 43 (2009) 831-841, doi: https://doi.org/10.1016/j.watres.2008.11.043.

7. K. Zhang, K. Farahbakhsh, Removal of native coliphages and coliform bacteria from municipal wastewater by various wastewater treatment processes: Implications to water reuse, Water Res. 41 (2007) 2816-2824, doi: https://doi. org/10.1016/j.watres.2007.03.010.

8. J. Radjenović, M. Matošić, I. Mijatović, M. Petrović, D. Barceló, Membrane Bioreactor (MBR) as an Advanced Wastewater Treatment Technology, u: D. Barceló, M. Petrovic (ur.) Emerging Contaminants from Industrial and Municipal Waste: Removal Technologies, Springer Berlin Heidelberg, Berlin, Heidelberg, 2008., str. 37-101.

9. F. Meng, S. Zhang, Y. Oh, Z. Zhou, H.-S. Shin, S.-R. Chae, Fouling in membrane bioreactors: An updated review, Water Res. 114 (2017) 151-180, doi: https://doi.org/10.1016/j. watres.2017.02.006.

10. E. Drazevic, S. Bason, K. Kosutic, V. Freger, Enhanced partitioning and transport of phenolic micropollutants within polyamide composite membranes, Environ. Sci. Technol. 46 (2012) 3377-3383, doi: https://doi.org/10.1021/es204188j.

11. D. Dolar, K. Košutić, D. Ašperger, Influence of adsorption of pharmaceuticals onto RO/NF membranes on their removal from water, Water Air Soil Pollut. 224 (2013) 1377, doi: https://doi.org/10.1007/s11270-012-1377-0.

12. Standard Methods for the Examination of Water and Wastewater, 19 $9^{\text {th }}$ Ed., American Public Health Association/American Water Works Association/Water Environment Federation, Washington DC, 1995.

13. M. Matošić, V. Crnek, H. K. Jakopović, I. Mijatović, Municipal wastewater treatment in a membrane bioreactor, Fresen. Environ. Bull. 18 (2009) 2275.

14. M. Mulder, Basic principles of membrane technology, $2^{\text {nd }}$ Ed., Kluwer Academic Publisher, Dordrecht, 1996.

15. K. Košutić, D. Dolar, B. Kunst, On experimental parameters characterizing the reverse osmosis and nanofiltration membranes' active layer, J. Membr. Sci. 282 (2006) 109-114, doi: https://doi.org/10.1016/j.memsci.2006.05.010. 


\section{SUMMARY}

\section{Treatment of Municipal Wastewater by Membrane Processes}

Davor Dolar, Marko Racar, Krešimir Košutić, Nina Čavarović, and Klara Karadakić

Industrialization, population growth, and urbanization are the main causes for the generation of increasing quantities of municipal wastewater (MWW) which, untreated, pose a serious threat to natural aquifers. In order to protect the environment and natural resources, it is necessary to use high-efficiency and environmentally friendly technologies for the treatment of MWW. The goal of this work was treatment of MWW with advanced membrane processes; membrane bioreactor (MBR) and nanofiltration (NF) and reverse osmosis (RO). Laboratory and pilot treatment of MWW with MBR resulted in a reduction of more than $92 \%$ in chemical oxygen demand (COD), biochemical oxygen demand $\left(\mathrm{BOD}_{5}\right)$, turbidity and suspended matter. The number of microbiological parameters decreased by $4.12 \log _{10}$ to $4.88 \log _{10}$. Subsequent treatment of MBR effluent with RO/NF membranes (XLE and NF270) further reduced all measured parameters.

\section{Keywords}

Municipal wastewater, membrane processes, membrane bioreactor, nanofiltration, reverse osmosis

Faculty of Chemical Engineering and Technology

Professional paper University of Zagreb

Marulićev trg 19

10000 Zagreb, Croatia 